\title{
Involving patients in decisions about preventive medication: a focus group study
}

\section{Ian Hill-Smith*}

General Practitioner; Stopsley Group Practice, Churchfield Medical Centre, 322 Crawley Green Road, Luton, Bedfordshire LU2 9SB

\section{Elspeth Mathie}

Research Fellow; Centre for

Research in Primary and

Community Care, University of

Hertfordshire, College Lane,

Hatfield, Herts AL10 9AB

\section{Paul Little}

Professor of Primary Care

Research; University of

Southampton, Aldermoor Health

Centre, Southampton S016 5ST

${ }^{*}$ Corresponding author:

Email: ian@azoth.demon.co.uk

Prim Care Cardiovasc J 2010; 3

$51-56$

doi: $10.3132 /$ pccj.2010.006

\section{Key points:}

- Previous research shows patients have unrealistic expectations of preventive medication and that many default long-term

- Informed choice requires that patients understand the balance of benefit against the risk, but imparting such information is difficult

- The focus groups showed the majority of participants had received very little or no information on the benefits or disadvantages

- Younger patients were receptive to being involved in decision-making, others trusted the doctor to recommend appropriate medication

- The preferred format is written text or graphics giving information specific to the individual

\section{Abstract}

Background: Patients may have unrealistic expectations of preventive treatment and frequently do not take long-term medication. Involvement of the patient in the decision to start such medication may improve this, but enabling an informed decision is notoriously difficult.

Aims: To explore patients' perceptions of preventive medication, the desire for informed choice and how this could best be achieved.

Method: Purposive sampling was used to select patients registered with one of two general practices in South England. Audio recording, transcription and computer-assisted textual analysis were conducted for focus group discussions.

Results: This was a small study, but the majority of focus group participants who had been prescribed a preventive medication said they received very little or no information about benefits and disadvantages when it was started. Some felt that doctors did not want to share information. Older participants thought that choice was over-rated, trusted their doctor to recommend appropriate medication and did not necessarily wish to be involved in the decision. Younger participants wanted to be more involved. However, even those who expressed little interest in involvement felt that personalised information compared with population norms comparing individuals to the 'average person' would be helpful. Written information specific to the individual and on how the medication or lifestyle changes might affect them was considered welcome.

Conclusions: Doctors need to be sensitive to patients' preferences for involvement in the decision-making process and for the way information on risk is shared. Providing written information specific to the individual patient is likely to facilitate shared decisions about preventive medication.

Keywords: patient participation; patient-centred care; primary prevention; risk; decision-making

\section{INTRODUCTION}

The aim of long-term preventive medication is to reduce the risk of illness, rather than hoping, against the odds, that the individual patient will necessarily benefit. ${ }^{1}$ We know from previous research that only about onequarter of people would take a drug offering $5 \%$ absolute risk reduction over five years. ${ }^{2}$ This was despite their being told that the hypothetical treatment was safe.

"With heart disease, study after study has shown that patients are nowhere as enthused about all this medication as their doctors are for prescribing it, with discontinuation rates of lipid-lowering therapy up to 50\% after one year and 85\% after two years. So, the fact that we can offer prevention isn't as simple as it seems." (David Haslam, The James Mackenzie Lecture 2006.3)

Some medical professionals suggest that one-third of people over the age of 55 could benefit from taking a polypill of preventive medication, ${ }^{4}$ but a substantial proportion of the public is giving a completely different message ${ }^{5}$ by taking the decision to stop recommended drugs. ${ }^{6,7}$ Resolving this issue is crucial if we are to target resources where they are most useful ${ }^{8}$ because, without acceptance from the patient, medication will be wasted or taken too erratically, or for too short a time, to reap any benefit. ${ }^{9,10,11}$ Alongside these pragmatic concerns, it is unethical to mislead patients into taking medication in the erroneous belief that it is bound to be good for them. ${ }^{12,13,14}$

This study aimed to explore patients' perceptions of preventive medication, to see if there is a desire for information that would enable an informed choice, and, if so, what form this information should take.

\section{METHODS}

A focus group discussion guide was developed by the lead researcher and then tested by a pilot focus group. Bedfordshire Local Research Ethics Committee approval was granted for the study. The nurse at each of the two participating practices recruited participants, who were invited by letter or opportunistically.

Participants had an initial meeting with the nurse to discuss the study aims, with examples of some formats used for providing medical information, including: a graphic document using smiley faces, an audio compact disc, a patient drug information leaflet, an extract from the Summary of Product Characteristics for a preventive drug for bone loss listing the benefits and frequency of side-effects, and a text document giving an individual's 
10-year risk of a heart attack related to lifestyle factors, blood pressure and cholesterol level plus a summary of side-effects of some antihypertensive drugs in common use. The style of the text document was similar to one suggested by Pignone, ${ }^{15}$ providing data specific to the individual patient followed by absolute risk, expressed as a percentage and approximation in integers (eg one in five) of an event within 10 years and what would happen to this figure if a risk factor changed, such as giving up smoking.

In February and March 2007, four focus groups each lasting two hours were held in two general practices in Letchworth and Luton. The groups were run by an independent researcher acting as moderator, and a medical health professional taking notes. Box 1 gives the outline discussion structure and Box 2 the example presentation styles. The discussions were recorded and transcribed. Refreshments and travel expenses were provided.

Following the constant comparative method, thematic analysis was an iterative process using techniques from a grounded theoretical approach, ${ }^{16}$ with categories emerging after systematic analysis of the textual discussion. Initially, manual coding was used and this began with initial familiarisation with the data. The coding was then entered into the computer package QSR NUD*IST (N6). This ordering of data facilitated the later identification of emerging issues raised by participants, identified recurrent patterns, and permitted comparisons with concepts present in the literature.

\section{Participants}

Purposive sampling was used to select patients from the computer registers of each practice who were likely to have a specific interest in preventive medication.

\section{Inclusion criteria}

- 18 years or older

- able to contribute to a focus group discussion in English

- able to attend the meeting venue

- people with a personal risk factor such as high blood pressure, hypercholesterolaemia, or diabetes, or

- people who have had a primary event such as a heart attack or stroke, or

- a relative of someone so affected, or

- someone who has experienced an adverse drug reaction from preventive medication

A spreadsheet was used to maximise the diversity within each group. The aim of this was not to attempt any subgroup analysis (the number of participants in any one category would be small) but to facilitate a broad range of opinion to be expressed in the focus group discussions. The commonest preventive medication being taken was an antihypertensive or a statin, or both. Some patients had been taking preventive medication for only a few months and others as long as 30 years.
Box 1. Outline of part of the discussion structure

What information is required about the benefit

to the individual patient?

to the patient as a member of a special risk group?

to the patient as a member of the population?

What information is required about the disadvantages

to the individual patient?

to everyone who takes the medication?

to everyone who takes any medication?

\section{Box 2. Presentation styles}

How should the information be presented to patients?

A variety of ways of presenting information can be used as examples for the group to consider, while leaving it open for the group to suggest an entirely new way to convey the information.

Example presentation formats: information sheets in text or graphics or both, audio cassette, video, one-to-one discussion with doctor or nurse.

Numerical / non-numerical.

Primarily text / graphics.

Chance or risk, number needed to treat / number needed to harm.

\section{RESULTS}

\section{Study participants}

Table 1 gives details of the participants. In total, 28 individuals took part in the study: 15 female and 13 male. All were resident in the UK; two were of Asian origin and one from Poland. The ages of the groups ranged from 46 to 90 years. Health deprivation scores were derived from Neighbourhood Statistics ${ }^{17}$ using the practice postcodes, ${ }^{18}$ with most patients from each practice living within one postcode area. The sample was a stable population who had lived in the area for many years. In addition to the 28 , four people declined the invitation because of the time of the afternoon meetings, and four accepted but did not attend.

Table 1. Demographic data for the focus group participants

\begin{tabular}{|c|c|c|c|c|c|c|c|}
\hline $\begin{array}{l}\text { Focus } \\
\text { Group }\end{array}$ & $\begin{array}{c}\text { Age } \\
\text { Range } \\
\text { (Yrs) }\end{array}$ & $\begin{array}{l}\text { Mean } \\
\text { Age } \\
\text { (Yrs) }\end{array}$ & M & $\mathrm{F}$ & Location & $\begin{array}{c}\text { Health } \\
\text { Deprivation } \\
\text { Index* }\end{array}$ & $\begin{array}{l}\text { Health } \\
\text { Deprivation } \\
\text { Rank* }^{*} \\
\text { (centile) }\end{array}$ \\
\hline FG1 & $56-90$ & 70.6 & 5 & 3 & Letchworth & -1.01 & $28,164(87)$ \\
\hline FG2 & $65-79$ & 73.0 & 2 & 3 & Letchworth & -1.01 & $28,164(87)$ \\
\hline FG3 & $56-77$ & 69.1 & 4 & 4 & Luton & -0.69 & 25,066 (77) \\
\hline FG4 & $46-67$ & 59.0 & 2 & 5 & Luton & -0.69 & $25,066(77)$ \\
\hline All & $46-90$ & 67.7 & 13 & 15 & & & \\
\hline
\end{tabular}

* UK Government Indices of Deprivation 2007 for Super Output Areas, rank 1 being the most deprived, rank 32,482 the least. 
Table 2. Frequency of inclusion criteria

\begin{tabular}{|l|c|c|c|c|c|}
\hline & \multicolumn{5}{|c|}{ Focus Group } \\
\hline Inclusion Criteria & $\mathbf{1}$ & $\mathbf{2}$ & $\mathbf{3}$ & $\mathbf{4}$ & Total \\
\hline Personal risk factor & 8 & 5 & 6 & 7 & 26 \\
\hline Primary event & 4 & 1 & 3 & 1 & 9 \\
\hline $\begin{array}{l}\text { Relative with risk factor } \\
\text { or primary event }\end{array}$ & 1 & 0 & 1 & 1 & 3 \\
\hline $\begin{array}{l}\text { Personal experience } \\
\text { of side-effects }\end{array}$ & 3 & 2 & 4 & 5 & 14 \\
\hline Total & $\mathbf{1 6}$ & $\mathbf{8}$ & $\mathbf{1 4}$ & $\mathbf{1 4}$ & \\
\hline
\end{tabular}

Table 2 shows the frequency of the clinical inclusion criteria for the four groups, with some participants fulfilling more than one criterion as a major reason for being invited.

\section{Information on starting preventive medication}

The majority of focus group participants who had been prescribed a preventive medication said that they had received very little or no information about benefits and possible disadvantages when it was started.

"I've been to see other doctors, they just write me out a prescription and say 'take this." [FG3]

"He [the doctor] just said, 'you know, it's going up and it won't come down and youd be well advised, he said 'you don't have to, but you'd be well advised to start taking blood pressure tablets." [FG2]

*** The quotes provided are from a range of individuals (males and females) in the sample.

$[\mathrm{FG}]$ indicates the discussion group. Examples were given of some recent consultations in which general practitioners (GPs) were providing more explanation, which was appreciated by participants.

"The doctor don't rush you ... no Dr X doesn't, no.

He writes it all down and gives you a copy, well I've got a copy,

explains everything, you know." [FG3]

\section{Perceived benefits of preventive medication}

There was some underlying scepticism from many participants about the statistics used to portray risk, in that they were either too complicated or simply irrelevant to them.

"You can look on the Internet and you would see waves and swathes of statistics in all of this. Who do you believe, how do you believe?" [FG1]

"I would have thought that if some form of medication is going to reduce the risk by whatever percentage it is, then it's worth taking it." [FG1]

The fourth focus group, of younger participants, was more positive about information containing percentages. Five of the seven participants in this younger group said they wanted more information about their own personal risk of heart attack. Some wanted to monitor the effect of their medication on their risk.

"But if you knew your percentage risk and you knew that that changed over ... like if you were taking them and two years later you see your percentage has gone down or gone up, then you can think around that a bit more can't you?" [FG4]

The majority of participants were not interested in statements about people who were similar to them, but only those that related to them personally.

"I'm not interested in anybody similar to me, I'm interested in $m e$ !" [FG3]

"But as you say it's personal to you, a person asking your particular situation is what you want isn't it really?" [FG4]

Only two of the 28 participants had received a personal risk assessment of their chance of having a heart attack. One participant said they had not realised it was possible to calculate an individual risk. A few participants acknowledged the difficulty of applying population data to the individual.

"You have to weigh up what that statistic means to you:

1 in 5 are you going to be the 1 in 5?" [FG4]

Participants were somewhat reluctant to identify what they themselves felt to be the benefits, and, instead, reported what their doctor had told them. A few said they felt healthier while taking the medication, but most said they noticed no difference to their health.

"When I was first diagnosed with it I didn't feel poorly and I don't feel poorly now." [FG4]

Only a few of the younger participants who monitored their blood pressure felt they had evidence of benefit.

"I mean the tablets dragged it [blood pressure] down with me, they've kept it down, there's no doubt about that, they do work." [FG4]

\section{Perceived disadvantages of preventive medicine}

Some participants denied side-effects, others did not recognise them, and some "put up" with them. It was noted that it could be difficult to attribute side-effects to a medication. Some people returned to their doctor asking for a change of tablets, while others felt that side-effects took time to "settle down".

\section{"I could live quite happily without knowing about side-effects because I could turn that round and attribute them to it. I'm going to stop taking that because my feet are warm. (Laughter)" [FG1] \\ "If you do get nasty side-effects, is it just a passing thing that your system will settle down and then they'll go?" [FG1]}

Some participants believed the effect of their tablets would diminish over time, so they should be changed after a certain period, or because there would be a newer, better alternative. 
"I think when you've been on a tablet a very long time I think your system gets used to it so it doesn't have any effect on it, you know after a long time, it doesn't help you as it should do." [FG4]

It was felt that the anxiety from reading about possible adverse reactions might be harmful, especially to someone with high blood pressure, and that a list of "frightening" side-effects could stop people taking necessary medication, or generate side-effects by suggestion.

"I think too much information is worrying." [FGl]

"I say 'no don't tell me what the side-effects are." [FG1]

\section{Information style}

Of the example materials, the text document giving an individual's 10year risk of a heart attack was the style that most people welcomed. Information on frequencies of side-effects was perceived as being too technical. The patient information leaflet fared little better because of its small print, technical language and similarity with other leaflets.

"And you tend then to just read a few lines and then, oh I can't be bothered with that, I can't see or get a magnifying glass out." [FG4]

"But I notice on a lot of these side-effects, when they say ... nearly every leaflet is the same isn't it? You know they say exactly the same things, whatever it is you're taking." [FG4]

The graphic with smiley faces received a mixed reception, with some liking its style while others thought it childish.

"I think that's a good idea, that diagram. Happy little faces and unhappy little faces." [FG2]

"It's short and to the point." [FG2]

"It looks very childish to me." [FG2]

Graphics were seen as a good way to improve the presentation of numerical information, but graphs were not.

"Information is always easier to receive visually." [FG4]

"It's like all the graphs ... you couldn't prove anything ..."

[FG1]

When participants referred to a numerical risk, they expressed this using numbers under 100, such as ' 1 in 10'. Larger numbers were seen as expressing remote risks and, as such, were lumped together as indicating that rare things occasionally happen, which was seen as inevitable anyway.

"...I would sort of almost dismiss it because it's only very occasional, youre 1 in 1000 ..." [FG1]

"I think on a personal level I'd just like to know there's a chance that 1 in every 100 people who take the medication develop a wheeze so I know if I develop a wheeze I'll do something about it" [FG4]

The audio compact disc was criticised for being difficult to refer back to in order to clarify points later.
"Sometimes you can't always remember everything that's been said anyway and having it written down ..." [FG2]

\section{The decision to treat or not}

The majority of participants, particularly the older ones, expected their GP to suggest medication only when it was necessary. Choice was thought to be over-rated.

"I would like more information but not the full medical details because I don't understand it. Choices are very over-rated, I mean we are not statisticians." [FG1]

If they were to be involved, they would want to compare themselves with the "norm". Participants saw this as quite different from population data. One participant wanted such information so that she could adapt her lifestyle as well as, or instead of, taking preventive medication.

"If they gave us the norm, if there is such a thing for a person of my age and my weight and all the rest ... perhaps then I could look at that and see where I am in the norm" [FG1]

Focus group 4 (with the youngest mean age) showed the most interest in personal risk and also demonstrated knowledge of personal blood pressure and cholesterol readings. It was suggested that patients could have access to their own medical records via the Internet, including a graph showing their data over time, and links to web sites where help with interpretation could be found.

\section{Choice of drug}

Focus group 4 suggested they might help in the selection of their own medication if provided with the contraindications and possible adverse effects of a list of drugs.

"So you can actually look and say well why can't I go on that one?" [FG4]

Although these participants wanted to be more involved they recognised that it was not always easy to know what to ask.

"If you ask, you get information, if you ask the question - but it's knowing the right question to ask" [FG4]

\section{DISCUSSION}

\section{Summary of main findings}

The majority of participants in this small study, particularly the older ones, thought they had little role in the decision to start preventive medication. They trusted their doctor and would take whatever medication they were given. They felt that any reduction in risk was worth having, without balancing this against possible disadvantages.

Younger participants wanted to be actively involved in decisionmaking, and some wanted interactive access to their own records, with ongoing feedback of the effects of medication on both their medical condition and their risk.

Personalised information was welcome, paradoxically even by those who expressed little interest in choice. Population data were dismissed 
as either irrelevant or too complex. The concept of an individual with the same risk factors was not considered an attractive way to impart information. What the participants wanted was their own, individual risk explained by comparison with the "norm". When numbers are used to explain risk, keeping them smaller than 100 helps people understand how the risk applies to them.

Many participants were not particularly interested in knowing about the disadvantages of medication. The more prominent concern was about the anxiety that can be caused by lists of side-effects, with suggestions of extreme ways to avoid this, such as denial that they existed or avoidance of reading the patient information leaflet altogether.

The response to example materials was to focus on the potential benefits to the individual and largely ignore information about disadvantages. This may be partly because relatively few people experience serious side-effects and minor ones can always be put down to something else. Graphics were welcomed, but not line graphs.

\section{Strengths and limitations of the study}

The major limitation of the study is the small number of participants, which makes the findings difficult to generalise. However, a great deal of information was obtained from each participant, adding to the depth of the findings. Qualitative research using analysis of focus group discussions can elucidate the reasons for perceptions and patterns of behaviour, and we have taken care not to de-contextualise words, which may misrepresent the meaning.

Participants gave their time freely and had no particular bias for or against medication, although it is possible that those who felt less favourable to the use of medication would be less likely to participate.

The two general practices involved are not typical of the country as a whole, although the focus groups covered a range of ages and demographic factors. The focus groups were held in the afternoon, biasing the participants towards people without a full-time occupation and towards those who had retired.

\section{Comparison with existing literature}

Although patient-centred consultations are welcomed by patients, ${ }^{19}$ patient choice is no guarantee of a good outcome, ${ }^{20}$ and patients have a preference for being involved in major decisions more than minor ones. ${ }^{21}$ Other studies have found that patients often do not wish to be involved, ${ }^{22}$ with $69 \%$ of people in an American study preferring to leave medical decisions to their doctors, and that the wish to be involved decreased with age and increased with education. ${ }^{23}$

A study of patients' preferences carried out in South London found that $45 \%$ of patients wanted their GP to be the main or only decisionmaker; $39 \%$ wanted the GP to share the decision and $16 \%$ wanted to be the main or only decision-maker. ${ }^{24}$ It was also found that GPs' perceptions of their patients' 'desire to be involved in decisions' were inaccurate two-thirds of the time. Our study supports these findings in that it was apparent that there was less interest in being involved in decision-making from many older participants.
Telling people about adverse effects may not change their use of medication, ${ }^{25}$ but a 2006 national survey of patients' experience in England found that $42 \%$ of respondents said they would like more information about side-effects. ${ }^{26}$ Our study suggests that doctors need to be sensitive to patients' preferences about the communication of side-effects.

Doctors have difficulty in communicating information about risk to patients, ${ }^{27,28,29,30,31}$ and yet such information is important to enable informed decisions. ${ }^{32,33}$ It is clear from this study that many patients find the statistics used to convey risk unhelpful and confusing. The format of data presentation is known to affect patients' decisions. ${ }^{34,35}$ One way around the dislike of large numbers is to use a standardised language of risk, as suggested by Calman in 1996. ${ }^{36}$ Another is to use graphics. Pictures can be seen as helpful,,$^{37.38,39,40}$ but decision aids using graphs have not been widely adopted. ${ }^{41,42}$ In this study text and graphics (but not graphs) were preferred to audio because they are easier to refer back to later for clarification.

\section{Implications for future research or clinical practice}

Historically, doctors have often not involved patients in the decision to start preventive medication. Participation is now expected, particularly by younger patients, but doctors need to remain sensitive to patient preferences for involvement in the decision-making. When patients want to be involved, the most helpful method of providing information is to individualise it. A comparable hypothetical person, or a population of such people is not felt to be helpful, but confusing. Text and graphics (but not graphs) were preferred to audio because they are easier to refer back to later for clarification. Future research could test the recommendations from this study by examining patients' responses to information given when they are offered preventive medication.

\section{Funding}

This work was supported by HertNet, Hertfordshire Primary Care Research Network Consortium, University of Hertfordshire, Hatfield, Herts AL10 9AB.

\section{Ethical Approval}

Bedfordshire Research Ethics Committee as part of the National Research Ethics Service granted approval. REC reference: 06/Q0202/14

\section{Competing Interests}

All authors declare that they have no competing interests.

\section{Acknowledgements}

We would like to thank the participants, Professor Mike Kirby for his encouragement and for providing one of the host practices, nurses Rhona Rollings and Delyth Williams for recruiting the participants, and Dr Natasha Larmie for taking notes in the focus groups.

\section{Contributors}

Ian Hill-Smith conceived the research idea, applied for funding and ethical approval, administered the research plan, took notes during the 
Letchworth focus group meetings, agreed the coding and thematic analysis, wrote the first draft of the paper and integrated comments and suggestions from the other two authors. Ian Hill-Smith is the guarantor. Elspeth Mathie facilitated all the focus groups, administered the transcription of the audio recordings, encoded the data, and performed the qualitative analysis. She contributed to writing the final paper as submitted.

Paul Little oversaw the research and gave guidance on methods and analysis. He contributed to writing the final paper as submitted.

\section{Non-authors}

Rhona Rollings, Practice Nurse, Stopsley Group Practice, recruited the participants in Luton.

Delyth Williams, Practice Nurse, The Surgery, Nevells Rd, Letchworth, Herts SG6 4TS, recruited the participants in Letchworth.

Dr Natasha Larmie, GP Registrar Stopsley Group Practice, took notes at the Luton focus group meetings.

Members of HertNet, Centre for Research in Primary and Community Care, contributed suggestions at the pilot run of a focus group.

Geoff Morgan, Practice Manager, Stopsley Group Practice, administered the funds.

\section{References}

1. Godlee F. Preventive medicine makes us miserable. BMJ 2005; 330(7497): 0-f doi: 10.1136/ bmi.330.7497.0-f.

2. Trewby PN, Reddy AV, Trewby CS, Ashton VJ, Brennan G, Inglis J. Are preventive drugs preventive enough? A study of patients' expectation of benefit from preventive drugs. Clin Med 2002; 2(6): 527-33.

3. Haslam DA. The James Mackenzie Lecture 2006. Br J Gen Pract 2007; 57(545): 987-93.

4. Wald NJ, Law MR. A strategy to reduce cardiovascular disease by more than $80 \%$. BMJ 2003; 326(7404): 1419.

5. Lewis DK, Robinson J, Wilkinson E. Factors involved in deciding to start preventive treatment: qualitative study of clinicians' and lay people's attitudes. BMJ 2003; 327(7419): 841.

6. LaRosa JH, LaRosa JC. Enhancing drug compliance in lipid-lowering treatment. Arch Fam Med 2000; 9(10): 1169-75

7. Howitt A, Armstrong D. Implementing evidence based medicine in general practice: audit and qualitative study of antithrombotic treatment for atrial fibrillation. BMJ 1999; 318(7194): 1324-7.

8. Heath I. Who needs health care - the well or the sick? BMJ 2005; 330(7497): 954-6.

9. Marteau TM, Kinmonth AL. Screening for cardiovascular risk: public health imperative or matter for individual informed choice? BMJ 2002; 325(7355): 78-80.

10. Marinker M, Shaw J. Not to be taken as directed. BMJ 2003; 326(7385): 348-9,

11. Horne R. Compliance, adherence, and concordance: implications for asthma treatment. Chest 2006; 130(Suppl): 65S-72S.

12. McCormack $P$, Levine $M$, Rangno RE. Patients offered treatment for $C H D$ need full information to make decision. BMJ 1998; 316(7136): 1021.

13. Getz L, Sigurdsson JA, Hetlevik I. Is opportunistic disease prevention in the consultation ethically justifiable? BMJ 2003; 327(7413): 498-500.

14. Mangin D, Sweeney $\mathrm{K}$, Heath I. Preventive health care in elderly people needs rethinking. BMJ 2007; 335(7614): 285-7.

15. Pignone $M$, Mulrow $C D$. Evidence based management of hypertension: Using cardiovascular risk profiles to individualise hypertensive treatment. BMJ 2001; 322(7295): 1164-6 [erratum appears in BMJ 2001; 323(7319): 993].

16. Silverman D. Interpreting Qualitative Data: Methods for Analysing Talk, Text and Interaction 2nd edn. London: Thousand Oaks/New Delphi: Sage, 2001.

17. http://www.neighbourhood.statistics.gov.uk.

18. Strong M, Maheswaran R, Pearson T. A comparison of methods for calculating general practice level socioeconomic deprivation. Int J Health Geogr 2006; 5: 29.

19. Little P, Everitt H, Williamson I, et al. Preferences of patients for patient centred approach to consultation in primary care: observational study. BMJ 2001; 322(7284): 468-72.

20. Bryant LD, Brown N, Bekker HL, House A. The lure of 'patient choice'. Br J Gen Pract 2007; 57(543): 822-6.

21. Mansell D, Poses RM, Kazis L, Duefield CA. Clinical factors that influence patients' desire for participation in decisions about illness. Arch Intern Med 2000; 160(19): 2991-6.

22. Robinson $A$, Thomson $R$. Variability in patient preferences for participating in medical decision making: implication for the use of decision support tools. Qual Saf Health Care 2001; 10(Supp1): i34-i38.

23. Arora NK, McHorney CA. Patient preferences for medical decision making: who really wants to participate? Med Care 2000; 38(3): 335-41.

24. Cox K, Britten N, Hooper R, White P. Patients' involvement in decisions about medicines: GPs' perceptions of their preferences. Br J Gen Pract 2007; 57(543): 777-84.

25. Haynes RB, Yao X, Degani A, Kripalani S, Garg A, McDonald HP. Interventions for enhancing medication adherence. Cochrane Database of Systematic Reviews 2005.

26. Picker Institute of Europe National Survey of Local Health Services 2006. Department of Health, London 2007.

27. Misselbrook D, Armstrong D. Thinking about risk. Can doctors and patients talk the same language? Fam Pract 2002; 19(1): 1-2.

28. Alaszewski A, Horlick-Jones T. How can doctors communicate information about risk more effectively? BMJ 2003; 327(7417): 728-31.

29. Sheridan SL, Pignone MP, Lewis CL. A randomized comparison of patients' understanding of number needed to treat and other common risk reduction formats. J Gen Intern Med 2003; 18(11): 884-92.

30. Walter FM, Emery JD, Rogers M, Britten N. Women's views of optimal risk communication and decision making in general practice consultations about the menopause and hormone replacement therapy. Patient Educ Couns 2004; 53(2): 121-8.

31. Walter FM, Emery J, Braithwaite D, Marteau TM. Lay understanding of familial risk of common chronic diseases: a systematic review and synthesis of qualitative research. Ann Fam Med 2004; 2(6): 583-94.

32. Gigerenzer $\mathrm{G}$, Edwards A. Simple tools for understanding risks: from innumeracy to insight. BMJ 2003; 327(7417): 741-4.

33. Heller RF, Buchan I, Edwards R, Lyratzopoulos G, McElduff P, Leger SS. Communicating risks at the population level: application of population impact numbers. BMJ 2003; 327(7424): 1162-5.

34. Hux JE, Naylor CD. Communicating the benefits of chronic preventive therapy: does the format of efficacy data determine patients' acceptance of treatment? Medical Decision Making 1995; 15(2): 152-7.

35. Misselbrook D, Armstrong D. Patients' responses to risk information about the benefits of treating hypertension. BJGP 2001; 51(465): 276-9.

36. Calman KC. Cancer: science and society and the communication of risk. BMJ 1996; 313(7060): 799-802.

37. Fortin JM, Hirota LK, Bond BE, O'Connor AM, Col NF. Identifying patient preferences for communicating risk estimates: a descriptive pilot study. BMC Med Inform Decis Mak 2001; 1: 2.

38. Edwards A, Elwyn G, Mulley A. Explaining risks: turning numerical data into meaningful pictures. BMJ 2002; 324(7341): 827-30

39. Trevena LJ, Davey HM, Barratt A, Butow P, Caldwell P. A systematic review on communicating with patients about evidence. J Eval Clin Pract 2006; 12(1): 13-23.

40. Goodyear-Smith F, Arroll B, Chan L, Jackson R, Wells S, Kenealy T. Patients prefer pictures to numbers to express cardiovascular benefit from treatment. Ann Fam Med 2008; 6(3): 213-7.

41. McCormack P, Levine M, Rangno RE. Primary prevention of heart disease and stroke: a simplified approach to estimating risk of events and making drug treatment decisions. CMAJ 1997; 157: 422-8

42. Edwards A, Elwyn G, Gwyn R. General practice registrar responses to the use of different risk communication tools in simulated consultations: a focus group study. BMJ 1999; 319(7212): $749-52$ 